\title{
A música em crônicas brasileiras traduzidas na França, do enraizamento ao estranhamento
}

\author{
Émilie Geneviève Audigier*
}

On ne bâtit rien sur la pierre, tout sur le sable, mais notre devoir est de bâtir comme si le sable était pierre. JORGE LUIS BORGES ${ }^{1}$

Organizar uma antologia de literatura estrangeira seria uma das formas mais criativas de tradução, pela releitura de contos inéditos em francês apresentados sob um ângulo diferente, compondo novo livro, atualizado ou ressignificado pela tradução? Na coletânea Vibrations Brasil, publicada pela editora Passage(s) em 2015, minha intenção foi juntar doze contos e crônicas inéditos na França de escritores brasileiros, alguns já canônicos - desde Machado de Assis, João do Rio e Lima Barreto, passando por Autran Dourado, José J. Veiga e João Antônio, até escritores contemporâneos representativos de diversos universos, como Milton Hatoum, Nei Lopes, Ronaldo Correia de Brito, Alberto Mussa, Paulo Lins e Beatriz Bracher. O motivo da vibração, ou seja, da música como expressão e linguagem, é o fio de Ariadne do livro. O volume traz uma apresentação sobre a concepção do livro que escrevi, La musique avant toute chose [A música antes de tudo] e um posfácio da professora Fernanda Coutinho, da Universidade Federal do Ceará, "Et la littérature tomba amoureuse de la musique" [E a literatura do

\footnotetext{
* Universidade Federal do Maranhão (UFMA).

${ }^{1}$ Traduzido por Paul e Sylvia Bénichou, « Fragments d'un évangile apocryphe », Éloge de l'ombre (1969).
} 
Brasil se apaixonou pela música], além de notas biobibliográficas sobre os autores e uma lista com referências e orientações bibliográficas, indicando antologias de literatura brasileira publicadas na França e no Brasil. A antologia foi publicada pela Editora Passage(s), uma editora francesa independente. ${ }^{2}$ Antes de iniciar a reflexão sobre as três crônicas escolhidas com desdobramento pelo procedimento da tradução em língua francesa, e vinculadas ao tema geral da música, vale pensar os contornos e a arte das antologias, de literatura nacional ou traduzida. Será a forma literária mais adequada para apresentar uma nova composição de contos inéditos no novo país de recepção, confrontando tradição e modernidade e forçando o leitor a adotar um novo olhar sobre a literatura traduzida?

\section{A arte das antologias traduzidas: definir o cânone ou criar um manifesto}

Qualquer que seja o bouquet literário, representativo, ou manifesto de novas estéticas, sempre haverá a questão da inclusão e exclusão dos textos, a arbitrariedade e o limite da seleção. A antologia realiza e mostra um pedaço de uma obra, um período, um gênero, um tema ou uma região geográfica (como na antologia traduzida Histoire d'amour d'Amérique Latine, da editora Métailié), um estilo (por exemplo, na Antologia da literatura fantástica, de Borges e Bioy Casares $^{3}$ ), uma língua, uma origem geográfica. Paul Wyczynski relembra a origem da palavra antologia (1992): «O vocábulo vem do grego, devido à fusão entre dois componentes: «antos » [flor] e «legein » [escolher]. No plano metafórico, diria que a origem etimológica permite conceber um sentido embelezado "bouquet de flores" ou um arranjo de flores escolhidas. No plano estritamente literário, a antologia supõe uma "escolha

\footnotetext{
2 A Editora Passage(s) conta com várias coleções: de relatos de viagem, clássicos francófonos, contemporâneos, literatura estrangeira, livros de ensaios de ciências humanas e livros infantojuvenis. A coletânea de contos Vibrations Brasil saiu na coleção Projectiles, de ficção curta, contos e crônica, coleção que coordeno desde 2014. Na coleção, foram publicados, entre outros, Lettres du Bhoutan, de Ragnar Helgi Oláfsson traduzidos do islandês por Jean-Chrsitophe Salaun, um livro de contos L'homme qui ne faisait rien, de Mehis Heinsaar traduzido do estoniano por Antoine Chalvin e um livro de contos de Dagny Gioulami, Toutes les histoires que je connais, traduites par Stéfanie Lanni assim como outras ficções francesas contemporâneas Cf. site. http://www.editionspassages.fr/projectiles/.

${ }^{3}$ BIOY CASARES, Adolfo; BORGES Jorge Luís \& OCAMPO, Silvina. Antologia da Literatura Fantástica. Trad. Josely Vianna Baptista. São Paulo: Cosac \& Naify, 2013.
} 


\title{
de textos significativos, representativos, importantes" ${ }^{4} \gg$. porteuse d'une « certaine idée » de la littérature. Reinaldo Santos Neves (1997, p. 42) as define assim:
}

\begin{abstract}
Mais que qualquer outra produção editorial, as antologias remetem constantemente à natureza do patrimônio, de sua constante redefinição, reavaliação e reabilitação durante o ato da transmissão, que é sua razão de ser. A antologia literária pretende preservar um patrimônio podando-o, pretende estendê-lo tornando-o acessível, muitas vezes resumindo-o para despertar curiosidade. Geralmente obra de um indivíduo, às vezes de um grupo restrito de autores, ela remete ao complexo problema da herança, que pode ser aceito na sua totalidade, denunciado ou reorganizado por meio de cessões parciais, de reinserções ou resgates. [...]. Além disso, a antologia é submetida à tensão constante de dois polos que não conseguem nunca se excluir absolutamente: sua função de conservação e preservação, por um lado, e, por outro, sua tendência ao manifesto. Ela pode buscar manter a tradição do cânone literário se expondo, e desse modo, com frequência, fundá-lo, ao passo que ela pensa apenas preservá-lo; como pode tender a proclamar a existência de uma literatura outra, tome esta forma da literatura estrangeira ou a de uma concepção diferente da literatura. Museu e manifesto, a antologia, em graus diversos, conserva necessariamente essas duas faces porque carrega, por sua natureza uma "certa ideia" da literatura ${ }^{5}$.
\end{abstract}

\footnotetext{
${ }^{4}$ Le mot « anthologie » fait penser spontanément à un choix de textes. Le vocable vient du grec, dû au fusionnement de deux composantes : anthos (fleur) et legein (choisir). À tout prendre métaphoriquement, on dirait que l'origine étymologique permet de concevoir un sens enjolivé : " bouquet de fleurs », «arrangement de fleurs choisies ». Au plan strictement littéraire, l'anthologie suppose un choix de beaux textes ou, si l'on préfère, un choix de textes significatifs, représentatifs, importants. prefácio à Littérature canadienne-française et québécoise: anthologie critique, Michel Erman (1992).

${ }^{5}$ Plus que toute autre production éditoriale, les anthologies renvoient constamment à la nature du patrimoine, de sa constante redéfinition, réévaluation et réhabilitation lors de l'acte de transmission qui est sa raison d'être. Ces questions sont d'autant plus pressantes que l'anthologie littéraire entend préserver un patrimoine en l'élaguant, l'étendre en le laissant accessible, le résumer en cherchant souvent à aiguiser la curiosité. Généralement œuvre d'un individu, parfois d'un groupe restreint d'auteurs, elle renvoie au problème complexe de l'héritage, qui peut être accepté dans sa totalité, dénoncé ou réorganisé au moyen de cessions partielles, de réemplois ou de rachats. [...] En outre, l'anthologie est soumise à la tension constante de deux pôles qui ne parviennent jamais à s'exclure absolument : sa fonction de conservation et de préservation d'une part et, de l'autre, sa tendance au manifeste. Elle peut chercher à maintenir la tradition d'un canon littéraire en s'exposant souvent de ce fait à le fonder, alors qu'elle croit seulement le préserver, comme tendre à proclamer l'existence d'une littérature autre, que celle-ci prenne la forme de la littérature étrangère, ou d'une conception différente de la littérature. Musée et manifeste, l'anthologie, à des degrés divers, garde nécessairement ces deux faces parce qu'elle est par essence porteuse d'une « certaine idée » de la littérature. In Mapa da literatura brasileira feita no Espírito Santo, Reinaldo Santos Neves: http://www.estacaocapixaba.com.br/2016/01/mapa-da-literatura-brasileira-feitano.html, acesso em 22/05/2020.
} 
A antologia tem, antes de tudo, uma função normativa, chamada função de "construção identitária", para que se ela se insira no cânone literário. Ela ajuda a construir a identidade de uma nação, a representação da literatura nacional de outra língua. Pascale Casanova comenta a importância das antologias como representação da literatura estrangeira, ilustrando o "gênio literário" de uma nação. A função de descrição de uma literatura nacional responde a algumas necessidades do público alvo.

Tal característica responde à sua função de manifesto, que consiste em defender o contrário da norma, de um grupo, valores intelectuais diferentes como afirma Wilson Alves-Bezerra (2011) em "Promessas antológicas: o conto latino-americano contemporâneo a partir de algumas antologias". Se trata então de uma amostra sincrônica, ou um panorama de escritores, contendo, em geral, escritores conhecidos e menos conhecidos. A antologia se torna, de certa forma, visão premonitória da paisagem literária futura, mas, evidentemente, não é a regra.

Deta Aude \& Dufour definem a antologia como um tipo de publicação "politextual", seja em jornal, revista, ou livro. Politextual por sua variedade de autores e textos, apresenta a função de salvar a ficção de forma curta, o poema ou o conto. Já Marie-Hélène Torres qualifica esses textos como "autorreflexivos", procurando outras formas de leituras dos contos, dentro de um contexto diferente. E Silvana Serrani, em Discurso e Tradução em antologias bilíngues (2006, p. 29), acrescenta:

\footnotetext{
As antologias têm tido papel relevante nas práticas letradas de gerações de leitores, na representação de literaturas nacionais, na confirmação ou transformação de cânones, na educação, no desenvolvimento da crítica, no aprofundamento de concepções de cultura etc. Isso fez com que em muitas sociedades, ao longo da história, o gênero tenha recebido especial consideração, materializada em projetos editoriais, educacionais, de tradução ou de pesquisa sistemática.
}

Marie-Hélène Torres, em Antologias, coletâneas e coleções, fala de um "gênero paradigmático da escrita compilada". No artigo intitulado "Discurso e Tradução em antologias bilíngues", evoca os autores de antologia como "criadores autorreflexivos". "São esses autores que quebram as formas petrificadas, os clichês que bloqueiam, às vezes durante décadas, 
a leitura verdadeiramente viva de uma literatura" (TORRES, 2016, p. 23). Ou seja, a antologia representa também o espaço da criação literária, para os leitores darem nova dimensão a textos retraduzidos. Como exemplo, na antologia Contes fantastiques d'Amérique Latine, publicado pela editora AnneMarie Métailié em 1999, Machado de Assis, pela primeira vez na França, é apresentado e lido em sua dimensão fantástica.

Essa ideia é reiterada por Paulo Henriques Britto, em “O tradutor como antologista" (2016, p.45). De fato, organizar uma antologia

obriga o poeta a exercer a tripla função de tradutor, poeta e selecionador de textos. Porém, as menções que fizemos ao paratexto nesse último exemplo nos lembra que há também um quarto papel a ser exercido pelo antologista: o de crítico. $\mathrm{Na}$ verdade, a atividade crítica já estava presente tanto no trabalho de seleção quanto no de tradução; mais de um autor já observou que não há crítica mais completa, mais exaustiva - nos dois sentidos da palavra "exaustivo" - que o trabalho de tradução.

Traduzir e organizar antologias impõem, de fato, um olhar crítico, uma vontade de interpretar com novo olhar.

A tradução de antologias exerce, assim, seu papel fundamental de interpretação do texto, estando intrínsecas, nesse caso, as ações de recontextualizar os textos e de permitir nova apropriação e ressignificação. A transformação que a tradução opera no texto, por ser o espaço por excelência do diálogo entre culturas, deve procurar nova restituição de sentidos e formas.

A partir dessas reflexões introdutórias sobre as problemáticas do tradutor antologista, me pergunto como os conceitos de estranhamento e enraizamento, dois movimentos a priori contrários que podem agir como um movimento pendular, ou umas tendências nitidamente marcadas por um lado, ou seu oposto, se entrecruzam na visão do autor, em seguido filtrado novamente pela mão do tradutor para finalmente chegar no leitor estrangeiro? 
Três crônicas sobre música de João do Rio, João Antônio e Milton Hatoum: do estranhamento ao enraizamento

À primeira vista, os três textos têm diversos pontos em comum: 1) são crônicas, 2) são escritas do ponto de vista do escritor, datadas e situadas no espaço, 3) têm a música por motivo (inscrita na antologia Vibrations Brasil). A música pode ser uma forma de expressão e encontro entre várias classes sociais (elite, em clube, ou música de rua, uma prática próxima à mendicidade em São Paulo, e passando pela música popular das rádios da época da classe média da Zona Norte do Rio, com Aracy de Almeida); 4) Os três estão inscritos num espaço definido: dois no Rio, e um em São Paulo, no bairro árabe.

Os três escritores escolhidos tratam, com mais ou menos ênfase, de questões de estranhamento e de enraizamento, dois conceitos que serão discutidos também através da tradução. Ou seja, queremos desenvolver uma dupla reflexão sobre as noções de estranhamento e enraizamento como temáticas do texto de partida.

As três crônicas encarnam o estranhamento e o enraizamento, tanto por seus temas como pelas próprias questões de tradução. A primeira crônica, de João do Rio, "Gente do music-hall" (1909), conta a história de uma fauna humana exótica e cosmopolita, constituída por artistas não convencionais, dentro de um music-hall no Rio de Janeiro. A segunda, de João Antônio, “A dama do encantado" (1996), um capítulo extraído de seu último livro A dama do encantado publicado pela editora Nova Alexandria, narra a história da cantora brasileira Aracy de Almeida na Zona Norte do Rio de Janeiro, com anedotas e depoimentos sobre a vida da cantora no final de sua carreira. A terceira, de Milton Hatoum "O bandolim e sua amada", em O observador à espreita, foi publicada pela Companhia das Letras de bolso, em 2013. É a história de um bandolinista de rua, que fabrica violões com material de recuperação, no bairro de imigrantes de São Paulo, onde o escritor vai para fazer pesquisa sobre imigrantes libaneses e armênios.

Vale apresentar o que já foi traduzido dos três escritores para a língua francesa. João Paulo Emílio Cristóvão dos Santos Coelho Barreto, apresentado na França como "o melhor representante da literatura 'arte nova' brasileira", foi traduzido apenas em uma antologia, em 1939, com seu 
conto "L'homme à la tête de carton", tirado do livro Rosário da Ilusão (1921), traduzido por Luiz Annibal Falcão, na Anthologie de quelques conteurs brésiliens, Le Sagittaire, 1939. Quanto a João Antônio, foi exclusivamente traduzido em antologias de 1983 a 2005. ${ }^{6}$ Milton Hatoum é um dos maiores escritores contemporâneos brasileiros reconhecido na França. Grande parte de sua obra foi traduzida: Récit d'un certain Orient (Seuil, 1993), Deux frères (Seuil, 2003), e pela editora Actes Sud Cendres d'Amazonie (2008) et Orphelins de l'Eldorado (2010 e 2015). Além dos romances, contos foram traduzidos em revistas, de 1992 a 2015, e em antologias 7.

Como os conceitos de estranhamento e enraizamento, duas questões em permanente tensão e que constituem a essência do processo tradutório, se confrontam nas traduções que escolhemos? Ou seja, refletimos a partir do enraizamento, como o fato de pertencer ao espaço, e do estranhamento, a distância ou o não pertencimento ao espaço, tanto literário (ser ou não história ou ficção) quanto ao espaço geográfico. Esses conceitos reverberam, relevantes ao se traduzir literatura, tratando de espaços literários, e por se tratar de textos traduzidos, ou seja, transpostos para outras língua e cultura, para outros lugares.

A crônica é uma narrativa com personagens fictícios ou reais, mas com embasamento histórico e social plausível. Pode ser considerada como um conjunto de notícias verdadeiras ou falsas, com propósitos às vezes desfavoráveis, que se propagam oralmente, como nas expressões em francês

${ }^{6}$ O conto "Le garçon à la caisse" do livro Meninão do caixote (1983), traduzido por Flávio Aguiar na revista Dérives nos 37-38-39, em 1983, sua crônica "O jogo do bicho" foi publicada na revista Autrement no 42, em 1990, sem o nome do tradutor. O conto "Lapa", trecho de Malagueta, perus e bacanaço (1963), foi traduzido por Jacques Thiériot na antologia Des nouvelles du Brésil, publicado pela Métailié em 1998. A crônica Merdoches" "'Merdunchos" crônicas trecho do livro Casa de loucos (1994), traduzido por Jean-Paul Giusti na revista Nouvelle Revue Française no 573, em 2005. Finalmente, o conto "Maria de Jesus de Souza", tirado do conto "Abraçado ao meu rancor" (1986), traduzido por Jean-Paul Giusti, na revista Europe, no 919-920. Também foi adaptado um filme O jogo da vida (1976), João Antônio (1976), com roteiro de João Antônio, a partir dos relatos Malaguetas, perus e bacanaço (1963), produzido por Maurice Capovilla. Na revista Dérives, n³7-38-39. « Nouvelles brésiliennes », Montréal, 1983.

${ }^{7} \mathrm{O}$ conto "Réflexion sur un voyage sans fin", traduzido por Claude Fages, em Europe n 758, em 1992. O conto "Une lettre de Bancroft", traduzido e apresentado por Michel Riaudel, em 2000. "Qui sont les sauvages?", traduzido e apresentado por Michel Riaudel, em La Nouvelle Revue Française n ${ }^{\circ}$ 573, 2005. "Arabesques brésiliennes », in Qantara, no 56, Institut du Monde Arabe, 2005. Nouvelle Revue Française, $n^{\circ} 573$ : «Les lettres brésiliennes », Éditions Gallimard, avril 2005. Finalmente, na antologia Brésil 25 20002015, organizada e apresentada por Luiz Ruffato. Paris : Éditions A.-M. Métailié, « Suite brésilienne », $\mathrm{n}^{\circ} 187,2015$. 
da "crônica galante, mundana, escandalosa", como na expressão défrayer la chronique, ou seja, violentar as convenções e chegar ao escândalo. Se o poema tem o dever de ser perfeito, no romance se aceita uma imperfeição formal; já na crônica, segundo Milton Hatoum, na definição que revela para a revista Cult, em 2013:

[...] é uma breve visão da realidade elaborada pela literatura. Pela mão de um escritor. É quase como uma breve aparição. É uma espécie de poesia do cotidiano. É o momento lírico do cotidiano. Mas nesse momento lírico cabe tudo. Cabe a política, cabe a sua visão sobre as coisas, sobre o tempo. A crônica tem mais força quando transcende o tempo presente, se transformando numa janela aberta para outros voos e outras viagens. (HATOUM, 2013, p. 36).

Na crônica, intervém a relação com o realismo, ou seja, com o real, a realidade de um lugar, vista através do escritor, jornalista, cronista. Para Milton Hatoum,

\begin{abstract}
Essa ambiguidade entre o real e o ficcional está sempre presente na literatura. Como diz um amigo meu, o Lourival Holanda, "você sempre paga um dízimo ao real". Não a real moeda, mas o real de realidade. O que importa é essa ambiguidade. É o que poderia ter acontecido. [...] Em algumas crônicas eu revelo traços e fontes de alguns personagens dos meus romances, [...] De algum modo, eles estão presentes nos romances, mas muito alterados e transformados. As crônicas são basicamente ficcionais (HATOUM, 2013, p. 39).
\end{abstract}

Paralelamente, João Antônio também é um cronista "realista" e com prosa extremamente fecunda, tratando do quotidiano e personagens da periferia de São Paulo e Rio de Janeiro. Ele viveu boa parte de sua vida de maneira "marginal", não convencional, se impregnando da linguagem da rua; sua experiência próxima ao povo e à língua popular falada nas ruas tornou sua linguagem extremamente criativa. Ele retrata a vida do povo, ele usa a língua mais radical de sua linguagem. Quando procura um editor, é recusado por fazer uso de uma língua totalmente oralizada, um linguajar de malandros e moradores de rua. 
A crônica já na época do João do Rio era muito comum. Quem escrevia eram poetas e escritores de toda parte. Mas João do Rio foi o primeiro repórter do Brasil a ver a cidade por dentro, explorando todas as classes sociais, malandros, mendigos, prostitutas, e descrevendo o carnaval e a vida dos artistas por dentro. Ele trouxe para a crônica elementos de narrativas literárias tradicionais: consegue usar "persona" e "máscaras" para falar delas de várias formas. Com sua "crônica reportagem", foi um cronista pioneiro no Brasil. Progressista, vanguardista, ele apoiou o voto das mulheres, o divórcio, leis que vieram a ser adotadas muios anos depois. Como negro e homossexual, e com sua postura de dândi, ele era um personagem da cidade do Rio, encarnando o Rio, e captando o espírito carioca.

O estranhamento seria um conceito diferente, mais próximo do distanciamento; em francês, evoca uma série de estados, indo da distância à curiosidade: étrange, étrangeté, écart, décalage, distancement, éloignement, détachement, étonnement, bizarrerie, curieux. Podemos dissociar o estranhamento no sentido comum, de desfamilliarizar a desfamiliarização, na medida em que no "estranhamento" existe o efeito de algum elemento de fora.

A origem está no conceito ostranênie (estranhamento), ou остранение, elaborado pelo formalista russo Viktor Chklóvski, amigo do poeta Vladímir Maiakóvski, aos vinte e quatro anos de idade, em "Arte como procedimento" ou "Arte como processo", publicado pela primeira vez em Poetika (1917). As professoras Myriam Ávila e Sandra Stroparo, em Poéticas do estranhamento, publicado na editora Arte \& Letra ${ }^{8}$ em 2015, pensa o estranhamento a partir da visão do filósofo tcheco, naturalizado brasileiro, Vilém Flusser, que considera como "condição de conhecimento". Para ele, "as pessoas só se apropriam do mundo ao criar um distanciamento. Não por acaso, ele utilizava a correspondência para pensar o estranhamento, que possibilita o diálogo. Ele tinha ideias ao trocar cartas com amigos" (STROPARO, 2015, p. 59). Ou seja, a correspondência, como a própria crônica, poderia ser uma

\footnotetext{
${ }^{8}$ A coletânea de artigos A poética do estranhamento, organizada por Sandra Stroparo, citando a definição da professora Myriam Ávila, in Teoria da literatura: formalistas russos (Porto Alegre, 1971) e em Todorov (Lisboa, 1999).
} 
forma de escrita do estranhamento, o lugar de relato de visões e sensações pessoais.

O estranhamento se torna uma maneira de observar, com olhos novos, o mesmo projeto que Milton Hatoum, João do Rio, e João Antônio propõem na descrição dos mundos musicais dos protagonistas na rua, no music-hall e na casa da cantora Aracy de Almeida. Mas como se situam o enraizamento e o desenraizamento dos três escritores?

Em primeiro lugar, o escritor João do Rio, já pelo nome, explicita o enraizamento em sua cidade. João Antônio representa o enraizamento, se identificando com o homem escritor e cronista ligado ao seu lugar, às cidades do Rio de Janeiro e de São Paulo. Para Milton Hatoum é diferente, pois saiu de Manaus para morar em São Paulo, uma "grande ruptura", além de ter morado na França. A questão é muito presente na obra dele, uma outra forma de expressar o exílio.

\begin{abstract}
A Amazônia é muito vasta, muito longínqua. Ela isola. Em São Paulo, eu estou mais próximo de meu editor e de meus leitores, no coração da vida cultural do país9. Minha bússola me indica sempre o norte. Como dizia Guimarães Rosa: “Sou donde eu nasci. Sou de outros lugares.” (HATOUM, 2016, p. 7)
\end{abstract}

Do ponto de vista da tradução e da relação com as línguas, além de sua identificação com o árabe de seu pai, Milton Hatoum cita, entre outros, o francês de sua avó e afirma: "mas também aprende-se sobre sua própria língua". Ou seja, é pelo distanciamento e estranhamento que se conhece a si mesmo. Sublinha o papel civilizatório da tradução, dando acesso às obras do patrimônio universal: “Quando se traduz menos, isto é ressentido, as sociedades decrépitas, perdendo o essencial".

Quanto a João do Rio, do ponto de vista da tradução, ele já mantém uma forte relação com as línguas e culturas estrangeiras, valorizando o cosmopolitismo da cidade do Rio e criando a fantasia de uma rica cidade multicultural dos anos 1920. Traduzir os traços do estrangeiro (europeu) e as influências francesas daquela época causa os riscos de ser interpretado na

\footnotetext{
9 "Quitter Manaus, saisi par un irrépressible désir de départ, fut "la grande rupture" de sa vie. Une séparation salutaire qui lui a permis plus tard d'être reconnu. "L'Amazonie est trop vaste, trop éloignée. Elle isole. À São Paulo, je suis plus près de mon éditeur et de mes lecteurs, au cœur de la vie culturelle du pays. »
} 
tradução como etnocentrismo ou tendência à "naturalização", como veremos. Quanto a João Antônio, toda a dificuldade na tradução reside nas referências culturais muito "ancoradas", enraizadas no cenário suburbano carioca, e consequentemente, mais difícil de verter, pois fazem parte da cultura alheia, ou com o risco à "exotização", exageração dos traços se tornando de certa forma "pitoresco" ou caricatural.

\section{Música e variações nas crônicas traduzidas}

A infinidade da linguagem, sempre reinventada, traz ao ato de escrever ressignificações, assim como para os matemáticos, as palavras e suas combinações infinitas. Vejamos alguns exemplos de tradução onde aparecem traços de estranhamento, ou de enraizamento na escrita do original, em "Gente de Music Hall" de João do Rio, tirado de Cinematographos, crônicas cariocas (1909). Como transcrever a estranheza que, no caso de João do Rio, se torna duplamente estrangeiro, por fazer diversas referências estrangeiras, entre outros, à cultura francesa? Antoine Berman, na revista Palimpsestes (1990) cria uma correspondência entre os conceitos de "naturalização" e "etnocentrismo" A naturalização consiste em tornar uma tradução bem acessível a seu novo público estrangeiro, veiculando códigos linguísticos ou referenciais que pertecem à cultura de recepção. Quanto ao etnocentrismo, ele indica um excesso de naturalização que procede à conversão do texto e a colocação de todas as referências do país estrangeiro ao alcance do público de recepção, em detrimento do texto e das referências de origem. 


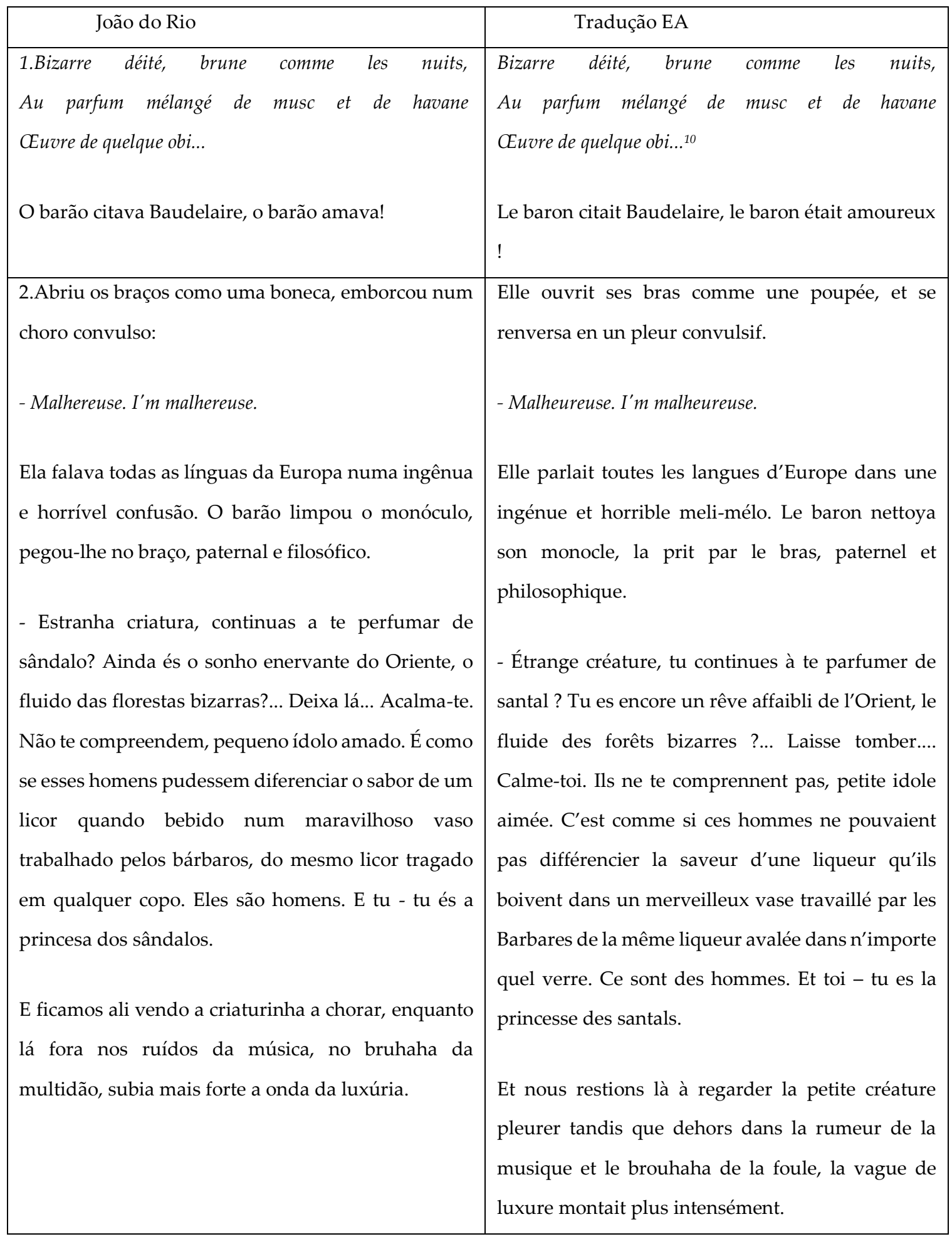

\footnotetext{
${ }^{10}$ Em francês no texto original.
} 
O primeiro elemento desta narrativa apresenta um ambiente cosmopolita do Rio com várias classes sociais, o exotismo dos personagens e a estranheza do mundo descrito no texto original. No texto, existem trechos inteiros em língua estrangeira, inglês e francês, ou seja, capaz de produzir o estranhamento para o próprio leitor brasileiro, apesar do Brasil ser um país de múltiplas línguas. A tradução reflete esse estranhamento por tratar de Baudelaire no Brasil, o próprio no outro. A citação do poema de Baudelaire, os empréstimos do francês como bruhaha, malheureuse, foram reproduzidos tais quais para o francês (ou seja, não traduzidos). Não procede num etnocentrismo ou uma naturalização. De certa forma, é um movimento de desenraizamento, um pedaço da França no Brasil da Belle Époque, e as influências francesas nas artes tropicalizadas no Rio de Janeiro.

Na crônica "A dama do encantado", de João Antônio, a história ocorre no meio do subúrbio carioca, numa classe média baixa. João Antônio se interessa pela vida de artistas populares que marcaram o Brasil, e com tom de realismo e verossimilhança. Como se trata de uma entrevista, ele usa a língua falada, a língua do jeito que a protagonista fala, o que marca a grande ruptura.

\begin{tabular}{|c|c|}
\hline João & Tradução EA \\
\hline $\begin{array}{l}\text { 1.Alguém escreveu por aí que eu exagero nas } \\
\text { histórias que conto. Exagero coisa nenhuma, é tudo } \\
\text { verdade. Conto o que é pra se contar. Tinha mais, é } \\
\text { que não me deixam abrir o verbo. E essa coisa de } \\
\text { Noel Rosa é preciso deixar claro que, se não fosse ele, } \\
\text { eu não estaria aqui cantando. Só ele acreditou em } \\
\text { mim, os outros me achavam uma escurinha que } \\
\text { queria... Bem. Uma escurinha qualquer. E teve gente } \\
\text { que disse até que eu desafinava, coisa que nunca } \\
\text { consegui fazer em mais de } 40 \text { anos de profissão! }\end{array}$ & $\begin{array}{l}\text { Quelqu'un a écrit quelque part que j'exagère dans } \\
\text { les histoires que je raconte. J'exagère pas un poil, } \\
\text { c'est qu'ils me laissent pas l'ouvrir. Et cette histoire } \\
\text { de Noel Rosa, faut bien clarifier une chose, s'il était } \\
\text { pas là, ch'serai pas là en train d'chanter. Lui seul a } \\
\text { cru en moi, les autres trouvaient que j'étais une } \\
\text { noiraude qui se la racontait... une noiraude } \\
\text { quelconque. Y a même des gens qui disaient que je } \\
\text { chantais faux, ce que j'ai jamais réussi à faire en } \\
\text { plus de } 40 \text { ans dans le métier! }\end{array}$ \\
\hline $\begin{array}{l}\text { 2. Nasci no Encantado, fui criada ali, tenho lá minha } \\
\text { casa com minhas flores e meus }\end{array}$ & $\begin{array}{l}\text { Je suis née à l'Encantado, j'ai grandi là, j'ai ma } \\
\text { maison là-bas avec mes fleurs et mes petits chiens }\end{array}$ \\
\hline
\end{tabular}




\begin{tabular}{|c|c|}
\hline $\begin{array}{l}\text { cachorrinhos de estimação. Ali eu fui menina, fui } \\
\text { pobre, dormi em cima de esteira. É uma casa térrea, } \\
\text { minha, cheia de azaléias na primavera e de } \\
\text { caramanchões; eu lá vou me sujeitar a viver dentro } \\
\text { de um apartamento? Não, compadre, não é por nada, } \\
\text { não. Mas esse babado de Zona Sul, apartamento, } \\
\text { quarto-e-sala... a sua tia aqui não embarca nessa } \\
\text { canoa. Depois, me criei no Encantado. Sabe, a gente } \\
\text { sente o calor de tudo isso. }\end{array}$ & $\begin{array}{l}\text { domestiques. Là-bas, j'ai été petite fille, j'étais } \\
\text { pauvre, j'ai dormi sur la paille. C'est une maison au } \\
\text { rez-de-chaussée, à moi, pleine d'azalées au } \\
\text { printemps et de tonnelles fleuries ; là-bas je vais } \\
\text { m'abaisser à vivre à l'intérieur d'un appartement? } \\
\text { Non, mon gars, pas du tout du tout. Mais cette } \\
\text { frime de la Zone Sud, appartement chambre et } \\
\text { salon... Vas pas me mener en bateau là. Ensuite, j'ai } \\
\text { grandi à l'Encantado. Tu sais, on sent que ça } \\
\text { chauffe tout ça. }\end{array}$ \\
\hline $\begin{array}{l}\text { 3. Cronistas apressados viram em Aracy apenas } \\
\text { irreverência. A gana de reportar o pitoresco e até o } \\
\text { picaresco esteve mais preocupada com a fofocagem } \\
\text { da suposição de que com a obra, a ponto de } \\
\text { confundirem nomes e locais. Até se envolveu o nome } \\
\text { de Getúlio Vargas, no Palácio do Catete, no Rio de } \\
\text { Janeiro, a prestar uma homenagem à cantora e a } \\
\text { receber uma de suas respostas irônicas. }\end{array}$ & $\begin{array}{l}\text { Des chroniqueurs empressés n'ont vu chez Aracy } \\
\text { que son irrévérence. Les travers du reporter, son } \\
\text { pittoresque et même son picaresque s'étaient plus } \\
\text { intéressés aux commérages des qu'en dira-t-on } \\
\text { qu'à son œuvre, au point de confondre les noms et } \\
\text { lieux. Ils se sont même occupés du nom de Getúlio } \\
\text { Vargas, au Palai du Catete, à Rio de Janeiro, qui a } \\
\text { rendu hommage à la chanteuse et reçu l'une de ces } \\
\text { réponses ironiques. }\end{array}$ \\
\hline
\end{tabular}

$\mathrm{Na}$ tradução, tentei respeitar os traços de oralidade. No primeiro exemplo, "exagera coisa nenhuma", traduzido por "j'exagère pas un poil", ou, recriando a informalidade "Não é por nada não", traduzido por "pas du tout du tout", com a repetição enfatizando a oralidade do discurso. "A sua tia aqui não embarca nessa canoa" foi traduzido por "tu vas pas me mener en bateau", que seria uma proposta de equivalente idiomático, com a "canoa" e "le bateau" em comum. No terceiro exemplo, a expressão idiomática "no momento o mingau anda grosso" tem por equivalente "en ce moment, la sauce ne prend pas ". Ou seja, tentei a todo custo manter o estrangeiro, o estranhamento, como defendem os críticos da tradução tal como Antoine Berman ou Walter Benjamin.

Quanto às referências culturais, são numerosas e de diversas naturezas, tratando do contexto político (Getúlio Vargas), musical (Noel 
Rosa, samba), geográfico (Copacabana, Palácio do Catete), o que traz ao leitor possibilidades diversas: primeiro a partir das notas que têm por função explicitar e documentar o leitor dos nomes próprios citados, para reinserilos na História cultural do país. Se não conhecer, ele pode procurar por ele mesmo a se informar melhor sobre cada elemento pertencendo ao contexto cultural brasileiro e carioca dessa época. $\mathrm{O}$ fato de nomear as ruas, os lugares, no olhar observador, neutro ou irônico, de um narrador, aliás, confirma seu estatuto de crônica.

O mesmo ocorre na crônica de Milton Hatoum intitulada "Bandolim", em que a questão da imigração árabe e armênia no Brasil já veicula o tema do desenraizamento e estranhamento.

\begin{tabular}{|c|c|}
\hline & \\
\hline $\begin{array}{l}\text { 1.Fiquei por ali, na calçada da rua Barão de } \\
\text { Duprat, observando o vendedor de água mineral. } \\
\text { Não era exatamente um camelô ou um } \\
\text { ambulante. Era um homem cansado. Magro e } \\
\text { pálido, sua força estava na voz. E a voz } \\
\text { significava: vontade de sobreviver. Mas não } \\
\text { parecia triste, nem derrotado. [...] E diante dos } \\
\text { policiais, pegava uma garrafa vazia, fingia que } \\
\text { era um microfone e começava a cantar um } \\
\text { chorinho. E que voz! Reconheci um dos } \\
\text { chorinhos porque é um hino de São Paulo: } \\
\text { jamais te esquecerei, do grande compositor e } \\
\text { violonista Antônio Rago. }\end{array}$ & $\begin{array}{l}\text { Je restai là, sur le trottoir de la rue Barão de Duprat à } \\
\text { observer le vendeur d'eau minérale. C'était pas } \\
\text { exactement un vendeur de babioles ni un vendeur } \\
\text { ambulant. C'était un homme fatigué. Mince et pâle, } \\
\text { sa force résidait dans sa voix. Et une voix qui } \\
\text { signifiait : l'envie de survivre. Mais il ne paraissait ni } \\
\text { triste ni abattu. [...] Et face aux policiers, il tenait une } \\
\text { bouteille vide, le tenant en microphone et } \\
\text { commençait à chanter un chorinho. Quelle voix! Je } \\
\text { reconnus l'un de ses chorinhos parce que c'était } \\
\text { l'hymne de São Paulo: Je ne t'oublierai jamais, du } \\
\text { grand compositeur et guitariste Antônio Rago. }\end{array}$ \\
\hline $\begin{array}{l}\text { 2.Raimundo da Silva Duprat, o único Barão de } \\
\text { Duprat, nasceu em Pernambuco e foi prefeito de } \\
\text { São Paulo na primeira década do século passado. } \\
\text { Não sei se foi um bom prefeito. Aliás, não é do } \\
\text { barão nem do ex-prefeito que quero falar. É que } \\
\text { para chegar ao assunto, devo mencionar a rua } \\
\text { Barão de Duprat, próxima ao formigueiro }\end{array}$ & $\begin{array}{l}\text { Raimundo da Silva Duprat, le seul Baron Duprat de } \\
\text { ce nom, est né dans le Pernambouc et a été maire de } \\
\text { São Paulo dans la première décennie du siècle passé. } \\
\text { Je ne sais pas s'il a été un bon maire. D’ailleurs, ce } \\
\text { n'est pas du baron ni de l'ex-maire que je veux parler. } \\
\text { Mais pour arriver au sujet, je dois mentionner la rue } \\
\text { Barão de Duprat, proche de la fourmilière humaine }\end{array}$ \\
\hline
\end{tabular}




\begin{tabular}{|l|l|}
\hline $\begin{array}{l}\text { humano da } \mathbf{2 5} \text { de Março. Agora que citei a rua, o } \\
\text { barão e o político, passo para o brasileiro comum. }\end{array}$ & $\begin{array}{l}\text { de la Rue du } 25 \text { mars. Maintenant que j'ai cité la rue, } \\
\text { le Baron et le politique, je passe au Brésilien commun. }\end{array}$ \\
\hline $\begin{array}{l}\text { 3.Tinha ido até a } \mathbf{2 5} \text { de março para fazer uma } \\
\text { pesquisa de campo sobre imigrantes árabes e } \\
\text { armênios que se estabeleceram há mais de um } \\
\text { século na famosa rua comercial e seus arredores. }\end{array}$ & $\begin{array}{l}\text { recherche de terrain sur les immigrants arabes et } \\
\text { arméniens qui s'étaient établis, il ya de cela plus d'un }\end{array}$ \\
& alentours. \\
\hline
\end{tabular}

Nesses trechos, observamos diversos indicadores geográficos (Rua Barão de Duprat, 25 de março, São Paulo), temporais (oito anos depois, dia 12 de dezembro) e culturais (chorinho, bandolim), elementos que ajudam o leitor brasileiro a se identificar, ou seja, procedendo ao enraizamento do Brasil, ou ao estranhamento, dependendo de que leitor brasileiro, e o leitor estrangeiro de tradução, no caso o leitor francês tende a imaginar melhor o distanciamento, com o singelo de uma cena do quotidiano de São Paulo, um músico de rua vendendo instrumentos com garrafa pet, e com apelido de Bandolim. No final da história, o gênio e a criatividade do músico de rua cai na miséria e na doença por conta de um amor que morreu. Na tradução, procedi a uma tradução a mais literal possível, recorrendo ao uso de algumas notas de cunho cultural, para ofertar ao leitor mais elementos culturais respondendo ao estranhamento causado pelas crônicas.

Finalizando, a missão de traduzir antologias se torna uma nova forma de leitura na criação. A representação da música brasileira em suas várias formas traduzidas em literatura, apresentou desafios de tradução, por seu enraizamento consubstancial à cultura brasileira, e pelo estranhamento causado no leitor brasileiro e no leitor da tradução. Como diz o filósofo e musicólogo Vladimir Jankélévitch, "Podemos pensar a partir da música, ou em música, ou musicalmente, a música sendo o advérbio da maneira do pensamento." 


\section{Bibliografia}

ALVES-BEZERRA, Wilson. Promessas antológicas: o conto latino-americano contemporâneo a partir de algumas antologias. Estudos de Literatura Brasileira Contemporânea, 38: 61-72, 2011.

AUDET, René; Geneviève Dufour. De la représentativité à la singularité. Fonctions de l'anthologie et du collectif de nouvelles. Voix et Images. Volume 35, 2(104): 27-42, 2010.

AUDIGIER, Emilie (Org.). Vibrations Brasil, Editions Passage(s) : Caen, 2017.

BEAUMARCHAIS, Jean-Pierre de; COUTY, Daniel (Orgs.). Anthologie des littératures de langue française. Paris: Bordas, 1988.

BRITTO, Paulo Henriques. O tradutor como antologista. In: TORRES MarieHélène; FREITAS Luana Ferreira de; COSTA Walter Carlos (Orgs.). Literatura Traduzida: antologias, coletâneas e coleções, v. 1. Fortaleza: Substânsia, 2016, p. 23-36.

BORGES Jorge Luis; BIOY CASARES Adolfo; OCAMPO Silvina (Orgs.). Antologia da Literatura Fantástica. Tradução Josely Vianna Baptista. São Paulo: São Paulo: Cosac e Naify, 2013.

CHURCHMAN, Philip H. The Use of Anthologies in the Study of Literature Author(s). The Modern Language Journal, Vol. 7, No. 3 (Dec., 1922), p. 149154. Published by: Wiley on behalf of the National Federation of Modern Language Teachers Association. Disponível em: http://www.jstor.org/stable/314201. Acesso em: 15 maio 2020.

EVERETT, Jane; Sophie Marcotte. De l'anthologie. Voix et Images, Volume 35, 2 (104): 7-15, 2010.

ERMAN, Michel. Littérature canadienne-française et québécoise : anthologie critique. Chomedey, Laval, Québec: Editions Beauchemin, 1992. FRAISSE, Emmanuel, Les anthologies en France. Paris: PUF, 1997.

MANGEON, Anthony. Miroirs des littératures nègres: d'une anthologie l'autre, revues. Gradhiva [online], 10। 2009. Disponível em: http://gradhiva.revues.org/1491. Acesso em: 22 jan 2013.

PINTO, Júlio PIMENTEL; Iegelski, F.; CHIARELLI, S. “Entrevista com Milton Hatoum". Intelligere, Revista de História Intelectual, São Paulo, v. 2, n. 2 [3], 2 p. 2-10. 2016. Disponível em 
http://www.revistas.usp.br/revistaintelligere/article/view/120279. Acesso em 20/05/2020.

SERRANI, Silvana. Discurso e tradução em antologias poéticas bilíngues A antologia Puentes/Pontes. In: GUERINI, Andréia; COSTA, Walter Carlos (Orgs.). Discurso e tradução. Tubarão: Copiart, 2014, p. $49-77$.

STROPARO Sandra; ÁVILA, Myriam (Orgs.). A poética do estranhamento. Curitiba: Arte e Letra, 2015.

TUHIWAI SMITH, Linda. Creating anthologies and other dangerous practices. International Research Institute for Maori and Indigenous Education, University of Auckland. Education Theory, Vol 50, no 4, 2000.

\section{Resumo}

A antologia Vibrations Brasil, organizada e traduzida por Émilie Audigier, publicada na editora Passage(s) em 2017, apresenta doze contos e crônicas sobre a temática da música. Três escritores e jornalistas de épocas e cidades diferentes: João do Rio (Paulo Barreto), com o Rio de Janeiro da Belle Époque, João Antônio na suburbana carioca dos anos 60, e Milton Hatoum no bairro de imigração armeniana e libanesa de São Paulo, são reunidos com um gênero em comum: a crônica literária brasileira. Estas três crônicas tratam com ênfase as questões do estranhamento e do enraizamento, dois conceitos que serão refletidos através de minha experiência de tradução destes autores. Partindo da exposição teórica sobre "antologia" e "estranhamento" de diversos teóricos, proponho neste artigo uma reflexão dos elementos de deslocamento no próprio original, mas sobretudo no processo da tradução.

Palavras-chaves: Crônicas brasileiras; Antologia; Música; Estranhamento; Enraizamento; João do Rio; João Antônio; Milton Hatoum.

\section{Résumé}

Dans l'anthologie Vibrations Brasil organisé et traduit par les soins d'Émilie Audigier, publiée aux éditions Passage(s) en 2017 présente douze nouvelles et chroniques dont le fil d'Ariane est la musique, présente dans chacun des textes courts. Trois écrivains et journalistes d'époque et de villes différentes : João do Rio (Paulo Barreto), avec Rio de Janeiro de la Belle époque, João Antonio, dans la banlieue de Rio des années 1960, et Milton Hatoum, du 
quartier d'immigration arménienne et libanaise de São Paulo, sont réunis dans un genre commun: la chronique littéraire brésilienne. Ces trois chroniques touchent aux questions de l'étrangéité et de l'enracinement, deux concepts qui seront pensés à travers mon expérience de traduction de ces auteurs. A partir de l'exposition de plusieurs théoriciens sur les contours de l'anthologie, je propose dans cet article une double réflexion des notions $\mathrm{d}^{\prime}$ « anthologie » et $\mathrm{d}^{\prime}$ " étrangeté », partant des éléments de la chronique, mais surtout de l'essence du procédé de traduction

Mots-clés: Chroniques brésiliennes; Anthologie; Musique; Étrangéité; Enracinement; João do Rio; João Antônio; Milton Hatoum. 